Article title: A Three-Component Solvent for the Treatment for COVID-19: Is the Data in Place for Clinical Trial? Authors: Thomas Manning[1], Jenu Thomas-Richardson[2], Steven Stogner[3]

Affiliations: Valdosta State University, USA[1], Forrest General Hospital and Hattiesburg Clinic, USA[2]

Orcid ids: 0000-0002-0862-1739[1], 0000-0001-8431-8865[2], 0000-0002-8154-5584[3]

Contact e-mail: tmanning@valdosta.edu

License information: This work has been published open access under Creative Commons Attribution License $\mathrm{http}: / / c r e a t i v e c o m m o n s . o r g / l i c e n s e s / b y / 4.0 /$, which permits unrestricted use, distribution, and reproduction in any medium, provided the original work is properly cited. Conditions, terms of use and publishing policy can be found at https://www.scienceopen.com/.

Preprint statement: This article is a preprint and has not been peer-reviewed, under consideration and submitted to UnisaRxiv for open peer review.

DOI: 10.25159/UnisaRxiv/000003.v1

Preprint first posted online: 26 January 2021

Keywords: COVID-19, treatment, protein, ethanol, alcohol 


\section{A Three-Component Solvent for the Treatment for COVID-19: Is the Data in Place for Clinical Trial?}

\section{Thomas J. Manning}

https://orcid.org/0000-0002-0862-1739

Valdosta State University, USA

tmanning@valdosta.edu

Steven W. Stogner

https://orcid.org/0000-0002-8154-5584

Forrest General Hospital and

Hattiesburg Clinic, USA

\section{Jenu Thomas-Richardson}

https://orcid.org/0000-0001-8431-8865

Valdosta State University, USA

\section{Abstract}

This letter outlines the potential use of a three-component solvent, with strong anti-viral properties, as an economical and efficient treatment of COVID-19. It focuses on the generation and delivery of the alcohol-based solvent as nanodroplets deep within a patient's lungs to reduce the viral load and potentially reduce the impact of a bradykinin or cytokine storm. The treatment is considered for compassionate use where other methods are not available or will not work.

Keywords: COVID-19; treatment; protein; ethanol; alcohol 


\section{Dear Editor}

The coronavirus has been involved in several documented outbreaks including Human CoV OC43 (1960), Human CoV HKU1 (2005), Human CoV 229E (1960), Human CoV NL63 (2004), Human SARS-CoV (2003), Human MERS-CoV (2012), and COVID-19 (SARS-CoV-2) (2019). Currently, there are no treatments that are universally recognized by the medical communities for COVID-19. This is not only a current but also a future concern.

The use of alcohol, specifically ethanol (EtOH), is ubiquitous with disinfection practices in healthcare facilities such as hospitals and medical practices, K-12 and higher education institutions, workplaces ranging from office buildings to manufacturing facilities, transportation hubs, and military bases worldwide. In addition, there is a significant volume of peer-reviewed literature that focuses not only on ethanol's general disinfection properties but also its anti-viral properties. Ethanol has been shown to have a direct impact on human coronaviruses such as Severe Acute Respiratory Syndrome (SARS) coronavirus, Middle East Respiratory Syndrome (MERS) coronavirus, or endemic human coronaviruses $(\mathrm{HCoV})$. These viruses can exist for several days on surfaces like plastic, steel, and glass.

It has been demonstrated that disinfectant agents can effectively reduce coronavirus infectivity in a very short time scale (<30 to 60 seconds). For example, ethanol, hydrogen peroxide, sodium hypochlorite, and benzalkonium chloride have been shown to be effective when applied to suspensions or on a surface. ${ }^{(1,2)}$ Of these chemicals, only ethanol can be inhaled and has a vast literature base describing its various successful uses in medical treatments, ranging from pharmacokinetic and pharmacodynamic data to its applications in clinical trials solubilizing various medications.

Our work with inhalation therapy started by examining delivery methods and matrices for treating pulmonary infections by Mycobacterium tuberculosis. Early in 2020 we shifted to an investigation that examined matrices and models that could lower viral infections in the lungs. Inhalation therapy for a pulmonary condition has the potential to be significantly more effective than a tablet-based route. Our proposal centers on using a rugged and tested delivery device, coupled with a molecular-based treatment that has been used effectively against viral infections, including COVID-19.

The treatment outlined here can be divided into two parts:

i. A solvent mixture that has demonstrated efficacy as a broad-spectrum anti-viral and has demonstrated activity against the coronavirus. It is an anhydrous composition composed of three alcohols: ethanol, propylene glycol and glycerol. 
ii. Electronic vaporization technology generates a vapor with a particle size small enough to penetrate deep into the lungs. Other inhalation techniques commonly used to deliver medical agents generate larger particles (i.e.> micrometer diameters) that lowers the efficiency of reaching the desired target deep within the lungs.

A compartmentalized view of the treatment follows.

\section{Goal}

The primary goal of this approach is the treatment of COVID 19 patients. It focuses on reducing the viral load in the lungs to a point where a patient's immune system can restore its efficacy. In addition, the use of the inhalation technique is to minimize a secondary effect such as a bradykinin or cytokine storm.

\section{Composition}

The treatment is composed of the alcohols ethanol, propylene glycol, and glycerol. All three alcohols have antiviral properties and are widely used in different medical, disinfection and cosmetic applications. Ethanol is the most studied of the three and its efficacy against coronaviruses is well known, inactivating the virus in 30-60 seconds with direct contact. ${ }^{(1,2)}$ A key point in the treatment is to avoid dilution of the alcohols with water before they arrive at the infected site. Also, other alcohols that might be considered, such as methanol or propanol, would have an unacceptable toxicity.

\section{Delivery}

The delivery of the anhydrous solvent to a specific location and with a certain particle size is critical. The inhalation technique utilized is electronic vaporization which generates the proper particle sizes $(100-500 \mathrm{~nm}) .{ }^{(3)}$ Other widely used inhalation techniques deliver larger particle sizes. The rapid heating and cooling are essential to form the small particles or nano-droplets needed to penetrate deep within the lungs. ${ }^{(4)}$ Typically, larger particles ( $>1$ micrometer) are deposited in the throat and upper portion of the respiratory system and would not reach the alveoli, a critical location to reduce the viral load. Electronic vaporizers are being used by millions of citizens for recreational uses today. They are well understood, reliable, economical, and readily available. ${ }^{(5,6)}$

\section{Physical Parameters}

Parameters such as surface tension, viscosity, and heat of vaporization are properties that help predict which liquids will produce the nanospheres needed for treatment. The heat of vaporization value for water $(2256 \mathrm{~kJ} / \mathrm{kg})$ compared to ethanol $(839 \mathrm{~kJ} / \mathrm{kg})$, glycerin $(974 \mathrm{~kJ} / \mathrm{kg})$ and propylene glycol $(914 \mathrm{~kJ} / \mathrm{kg})$ provides insight into why it can 
burn tissue, and its presence should be avoided in the solvent composition (see Table 1). In addition, when a nanodroplet interacts with a virus's particles, specifically its proteins, there is an exchange between the water in the protein and the alcohols. This exchange will result in an equilibrium, or water/alcohol exchange; $\left(\mathrm{H}_{2} \mathrm{O}\right.$ (protein) $<==>$ $\mathrm{ROH}$ (nanodroplet)), which results in a shift in the shape and function of the protein.

Table 1: Physical parameters for some of the key solvents included and related to the treatment.

\begin{tabular}{|c|c|c|c|c|c|c|c|c|}
\hline Species & $\begin{array}{c}\text { Empirical } \\
\text { formula }\end{array}$ & $\begin{array}{c}\text { Mol. } \\
\text { Weight }\end{array}$ & $\begin{array}{c}\text { Specific } \\
\text { Density }\end{array}$ & $\begin{array}{c}\text { Surface } \\
\text { Tension } \\
\text { (dynes) }\end{array}$ & $\begin{array}{c}\text { Viscosity } \\
\text { (mPa·s) }\end{array}$ & $\begin{array}{c}\text { Dipole } \\
\text { moment (D) }\end{array}$ & BP & $\begin{array}{c}\text { Heat of } \\
\text { Evaporation } \\
\text { (kJ/kg) }\end{array}$ \\
\hline Ethanol & $\mathrm{C}_{2} \mathrm{H}_{6} \mathrm{O}$ & 46.07 & 0.787 & 22 & 1.36 & 1.69 & $78.3{ }^{\circ} \mathrm{C}$ & 839 \\
\hline $\begin{array}{c}\text { DMSO } \\
\mathrm{C}_{2} \mathrm{H}_{6} \mathrm{OS}\end{array}$ & 78.13 & 1.095 & 42.9 & 1.82 & 3.96 & $189{ }^{\circ} \mathrm{C}$ & 678 \\
\hline $\begin{array}{c}\text { Propylene } \\
\text { glycol }\end{array}$ & $\mathrm{C}_{3} \mathrm{H}_{8} \mathrm{O}_{2}$ & 76.1 & 1.033 & 45.6 & 39.1 & 2.27 & $188.2{ }^{\circ} \mathrm{C}$ & 914 \\
\hline Wlycerol & $\mathrm{C}_{3} \mathrm{H}_{8} \mathrm{O} 3$ & 92.09 & 1.257 & 76.2 & 743 & 2.56 & $290{ }^{\circ} \mathrm{C}$ & 974 \\
\hline & $\mathrm{H}_{2} \mathrm{O}$ & 18 & 1.00 & 72 & 1.00 & 1.86 & $100{ }^{\circ} \mathrm{C}$ & 2256 \\
\hline
\end{tabular}

Note: DMSO is representative of compounds we also considered that are widely used in various medical applications, have anti-viral properties, and could potentially be administered at low levels.

\section{Mechanisms and Targets}

While a complete mechanism of action for the inactivation of proteins by alcohols is not fully understood, the ability of ethanol to dehydrate and denature them is well known. While a nonselective process, it is anticipated that proteins such as the spike proteins on COVID-19, the ACE2 receptor protein in lung cells, and the protein(s) associated with 
bradykinin and cytokine storms could be impacted. Glycerin has antimicrobial and antiviral properties and is an FDA approved treatment for wounds. Propylene glycol has a number of applications, including the preservation and isolation of genetic material such as DNA and RNA, used to solubilize drugs in topical, oral, and injectable medications, and has strong hygroscopic properties.

\section{Dose}

In recent communications, we provide calculations related to the medicinal impact that microliters of ethanol delivered by inhalation therapy could have on a viral load ${ }^{(5,6)}$ The toxicity of each substance is well known when given orally and inhaled. Electronic vaporizers not only provide a method to generate nanodroplets but also allow for a specific dose to be delivered with each inhalation. There is an upcoming Phase III clinical trial slated for the use of ethanol with aspirin to treat COVID-19 (NCT04554433), and a second trial that will use an electronic vaporizer to deliver ethanol to patients in an unrelated application (NCT03826303). The impact of electronically delivered glycerol and propylene glycol have also been studied in detail and health concerns seem to be focused on a long-term application, and not a short-term treatment (days).

\section{Application}

The electronic delivery devices are a tested technology, the solvents' medicinal activity are well established and used in many products, and there is a critical need for COVID-19 treatments. This may qualify for a compassionate use application for a COVID-19 patient in severe distress that has no approved treatment options.

The three key parameters for the treatment are:

i. That the alcohol treatment is anhydrous when delivered. Any other form that might dilute the sample before it reaches the diseased area, such as ingestion or intravenous, would not work.

ii. An electronic vaporization technique that generates droplets smaller than 500 nanometers, by rapidly heating and cooling the sample for inhalation therapy. The technology is well understood, economical, and ready for use.

iii. The physical, chemical, and biological characteristics of the three solvents are balanced to allow for a composition that is not toxic at the levels delivered, forms nano-droplets, reaches the diseased area with no water, and has a strong efficacy against a viral infection.

Millions of world citizens inhale two or three of the alcohols outlined here from an electronic vaporizer. The alcohols have well-known efficacies and have FDA approval for different applications. A typical treatment might last five to seven days and involve a 2:1:1 ratio of the three alcohols (EtOH, PG, GLY, respectively), with each inhalation 
set utilizing approximately 0.75 milliliters, one to three times per day. This letter asks a basic question: Is the treatment for COVID19 already in useand right in front of us?

In the appendix (below), the first documented use of an alcohol treatment for COVID19 patients is outlined. This was based on the use of ethanol with a standard inhalation device.

Respectfully submitted

Thomas J. Manning, Jenu Thomas-Richardson, and Steven W. Stogner

\section{Acknowledgements}

We would like to thank our respective institutions, Valdosta State University and Forrest General Hospital and Hattiesburg Clinic, for their support at various levels with these projects. We would like to thank our collaborators that provided us with different types of expertise and support, including Dr. Dennis Phillips of the PAMS lab at the University of Georgia, Dr. Greg Wylie of the NMR lab at Texas A\&M University, Dr. Jose Vazquez of the Infectious Disease unit at the Medical College of Georgia in Augusta, Dr. Randall Brown and Dr. George S. Staton at the South Georgia Medical Center (Valdosta, GA), and Dr. Tsumoru Shintake at the Okinawa Institute of Science \& Technology Graduate University (Okinawa, Japan).

\section{References}

1. Kampf G, Todt D, Pfaender S, Steinmann E. Persistence of coronaviruses on inanimate surfaces and their inactivation with biocidal agents. J Hosp Infect 2020; 104(3):246-51. PMID: 32035997. https://doi.org/10.1016/j.jhin.2020.01.022

2. Gerlach M, Wolff S, Ludwig S, Schäfer W, Keiner B, Roth NJ et al. Rapid SARS-CoV-2 inactivation by commonly available chemicals on inanimate surfaces. J Hosp Infect 2020; 106(3):633-4. PMID: 32916211. https://doi.org/10.1016/j.jhin.2020.09.001

3. Mulder HA, Patterson JL, Halquist MS, Kosmider L, Turner JBM, Poklis JL et al. The effect of electronic cigarette user modifications and e-liquid adulteration on the particle size profile of an aerosolized product. Sci Rep 2019; 9(1):10221. PMID: 31308389. https://doi.org/10.1038/s41598-019-46387-2

4. Danel V. Airborne particulate matter and their health effects: Encyclopédie de l'Environment; 2019. Available from: URL: http://www.encyclopedieenvironnement.org/?p=9225.

5. Manning TJ, Thomas-Richardson J, Cowan M, Thomas-Richardson G. Should ethanol be considered a treatment for COVID-19? Rev Assoc Med Bras (1992) 2020; 66(9):1169-71. PMID: 33027439. https://doi.org/10.1590/1806-9282.66.9.1169 
6. Manning TJ, Thomas-Richardson J, Cowan M, Beard T. Vaporization, bioactive formulations and a marine natural product: different perspectives on antivirals. Drug Discov Today 2020; 25(6):956-8. PMID: 32325124.

https://doi.org/10.1016/j.drudis.2020.04.010

\section{Appendix}

Dr. Steven Stogner, a pulmonary and critical care physician at Forrest General Hospital and Hattiesburg Clinic (Hattiesburg, Mississippi, U.S.), treated COVID-19 patients with inhaled ethyl alcohol. His results are summarized below (unpublished data). Dr. Stogner shared this data with our group and others and has agreed to it being used as an appendix in this submission.

Of necessity and compassionate use, a weight-based nebulized ethyl alcohol regimen was offered to hospitalized non-intensive care unit patients with acute hypoxemia due to confirmed COVID-19, to be used at the sole discretion of the physician. From April through December 2020, the medical charts of 306 patients were retrospectively reviewed. Of these patients, 81 were treated with ethyl alcohol, and 225 randomly selected patients were not. Both groups were similar in average age, body-mass index, gender distribution, and co-morbidities, and most patients in both groups had received other therapy including one or more of remdesivir, tocilizumab, azithromycin, convalescent plasma, or dexamethasone. Pre-treatment hypoxemia was considerably worse in the alcohol-treated group $(\mathrm{p}<0.0001)$. Outcomes review revealed the alcoholtreated group to have a decreased average length of stay (6.88 vs 9.88 days; $p=0.033$ ), inpatient mortality $(7.4 \%$ vs $17.8 \%$; $\mathrm{p}=0.029)$, progression of hypoxemia requiring transfer to ICU $(8.6 \%$ vs $14.7 \% ; \mathrm{p}=0.185)$, and need for intubation for invasive mechanical ventilation $(6.2 \%$ vs $12 \% ; \mathrm{p}=0.203)$. The alcohol-treated group also had a greater improvement in pre-treatment hypoxemia compared to discharge $(28.4 \% \mathrm{vs}$ $3.0 \% ; \mathrm{p}=0.057)$, and less frequent need for supplemental home oxygen $(45.7 \% \mathrm{vs}$ $64.4 \% ; \mathrm{p}<0.00001)$. Other benefits found in the alcohol-treated group included the ability to be discharged back to home $(81.4 \%$ vs $40.9 \%$; $\mathrm{p}<0.00001)$ as opposed to requiring subsequent admission for ongoing care at another healthcare facility, i.e. longterm acute care, etc. $(6.2 \%$ vs $38.2 \%$; $<<0.00001)$. These findings are very promising, but randomized controlled trials are needed to confirm the benefits of inhaled ethyl alcohol in the treatment of COVID-19. 